\title{
Upregulation of microRNA135a-3p and death receptor 5 plays a critical role in Tanshinone I sensitized prostate cancer cells to TRAIL induced apoptosis
}

\author{
Eun Ah Shin ${ }^{1, *}$, Eun Jung Sohn ${ }^{1, *}$, Gunho Won ${ }^{1}$, Jeong-Un Choi ${ }^{1}$, Myongsuk Jeong ${ }^{1}$, \\ Bonglee Kim ${ }^{1}$, Min-Jeong Kim ${ }^{1}$ and Sung-Hoon Kim ${ }^{1}$ \\ ${ }^{1}$ Cancer Preventive Material Development Research Center, College of Oriental Medicine, Kyung Hee University, Seoul, South \\ Korea \\ * These authors equally contributed to this work \\ Correspondence to: Sung-Hoon Kim, email: sungkim7@khu.ac.kr
}

Keywords: TRAIL sensitizer, tanshinone I, apoptosis, DR5, miR135a, prostate cancer

Received: April 12, $2014 \quad$ Accepted: June 29, 2014

Published: June 30, 2014

This is an open-access article distributed under the terms of the Creative Commons Attribution License, which permits unrestricted use, distribution, and reproduction in any medium, provided the original author and source are credited.

\section{ABSTRACT}

Though tumor necrosis factor related apoptosis inducing ligand (TRAIL) has been used as a potent anticancer agent, TRAIL resistance is a hot-issue in cancer therapy. We investigated the antitumor mechanism of Tanshinone $I$ to sensitize prostate cancer cells to TRAIL. Comibination of Tanshinone I and TRAIL exerted synergistic cytotoxicity, increased cleaved PARP, sub G1 population, the number of TUNEL positive cells, activated caspase 8, 9 and ROS production in PC-3 and DU145 cells. Of note, combination of Tanshinone I and TRAIL enhanced the protein expression of death receptor 5 (DR5) and attenuated anti-apoptotic proteins. RT-PCR and RT-qPCR analyses confirmed that co-treatment of Tanshinone I and TRAIL up-regulated DR5 and microRNA 135a-3p at mRNA level or activity of DR5 promoter and attenuated phosphorylation of extracellular signal regulated kinases in PC-3. Conversely, the silencing of DR5 blocked the increased cytotoxicity, sub G1 population and PARP cleavages induced by co-treatment of Tanshinone I and TRAIL. Interestingly, miR135a3p mimic enhanced DR5 at mRNA, increased PARP cleavage, Bax and the number of TUNEL positive cells in Tanshinone I and TRAIL cotreated PC-3. Overall, our findings suggest that Tanshinone I enhances TRAIL mediated apoptosis via upregulation of miR135a-3p mediated DR5 in prostate cancer cells as a potent TRAIL sensitizer.

\section{INTRODUCTION}

Prostate cancer is one of the most common cancers in men worldwide [1]. Most prostate cancer related deaths result from cancer metastasis, the spread of cancer from the prostate to other organs, bones and lymph nodes [2]. Though anti-cancer drugs such as Eulexin, Flutamide and Nilandron have been used for treatment of prostate cancer, their side effects have still occurred. Recent studies reported that TRAIL and microRNA (miR)s were suggested as potential biomarker or therapeutic potential in prostate cancer cells [3].

TNF-related apoptosis-inducing ligand (TRAIL) (Apo2 ligand [Apo2L]) that is a member of TNF superfamily was known to induce two death receptor DR4 (TRAIL-R1) and DR5 (TRAIL-R2) [4, 5]. There are accumulating evidences that TRAIL resulted in cell death in various cancer cell types such as colon, [6] ovarian [7] or hepatocellular carcinoma cells [8] as a selective anticancer agent.

MicroRNAs, small noncoding RNAs, play critical roles in oncogene, tumor suppressor, or apoptosis via inhibition of translation or degradation of target molecules. Recent studies showed that microRNAs modulate TRAIL induced apoptosis in cancer cells such as breast cancer or ovarian cancer $[9,10]$.

Cryptotanshinone, Tanshinone I, and Tanshinone IIA were known as the three major bioactive compounds from Dansen, the dried roots of the medicinal plant Salvia miltiorrhiza [11] that has been traditionally used for treating cardiovascular diseases [12]. Recent study reported that Salvia militiorrhiza with TRAIL 
showed evident cytotoxicity against the human lung adenocarcinoma cell line A549 and ovarian adenocarcinoma cell line [13]. Though Tanshinone I was shown to exert anti-cancer effects in non-small lung cancer [14], and breast cancer cells [15], its anti-tumor mechanism was not fully understood in prostate cancer cells.

MicroRNAs are regulated in prostate cancer and are expressed between androgen-dependent and androgenindependent metastatic prostate cancer cells [16, 17]. MiR135a is downregulated in androgene-dependent versus androgene-independent prostate cancer cells [18]. Though miR-135a functions in a tumor suppressor in several cancer cells such as renal cell carcinoma [19] or glioma cell [20], it has not fully investigated in prostate cancer cells. Thus, in the present study, the underlying apoptotic mechanism by combination of Tanshinone I and TRAIL was studied mainly in highly aggressive DU145 and PC-3 prostate cancer cells in association with upregulation of death receptors and microRNA $135 \mathrm{a}-3 \mathrm{p}$.

\section{RESULTS}

\section{Tanshinone I and TRAIL synergistically enhanced the cytotoxic effect in prostate cancer cells}

To evaluate the cytotoxic effect of Tanshinone I or TRAIL, MTT assay was carried out in human prostate cancer cell lines such as PC-3, DU145 or M2182 cells. To examine the synergistic cytotoxic activity of Tanshinone I and TRAIL, various concentrations of Tanshinone I ( 0 , $20,40,80 \mu \mathrm{M})$, and/ or TRAIL $(0,25,50 \mathrm{ng})$ were treated for $24 \mathrm{~h}$ in three prostate cancer cells. As shown in Fig 1A, combination of Tanshinone I and TRAIL synergistically exerted the cytotoxicity in three all prostate cancer cells. However, though M2182 cells were more susceptible to combination of Tanshinone I and TRAIL than PC-3 and DU145 cells, we performed further mechanistic study mainly in PC-3 and DU145 cells, based on previous evidences[21, 22] that PC-3 and DU145 cells were known to be more aggressive and chemoresistant to TRAIL. The significant synergy by combination of Tanshinone I and TRAIL was confirmed in PC-3 cells by using Chou and Talalay equation method, since combination of Tanshinone I and TRAIL (20 ng) showed significant combination Index (CI) values, 0.053 and 0.085 below 1 at the concentrations of 40 and $80 \mu \mathrm{M}$ of Tanshinone I, respectively (Figure 1B).
Combination of Tanshinone I and TRAIL dramatically induced apoptosis in prostate cancer cells

To determine whether the cytotoxicity by cotreatment of Tanshinone I and TRAIL was due to apoptosis induction, FACS analysis and TUNEL assay were carried out in PC-3 or DU145 cells. As shown in Fig $1 \mathrm{C}$, the co-treatment of Tanshinone I and TRAIL increased the population of sub-G1 DNA contents compared to Tanshinone I or TRAIL alone in PC-3 cells. Similarly, the co-treatment of Tanshinone I or TRAIL in DU145 cells increased the population of sub-G1 DNA contents in PC-3 and DU145 cells (Fig 1C) by FACS analysis which was similarly obtained by TUNEL assay (Fig 2A or B). The numbers of TUNEL positive cells were significantly increased by combination of Tanshinone I and TRAIL in both PC-3 and DU145 cells compared to Tanshinone I or TRAIL alone (Fig $2 \mathrm{~A}$ and $\mathrm{B}$ ).

Combination of Tanshinone I and TRAIL activated PARP and caspase 8 , regulated the Bcl2 family proteins and increased the level of ROS in PC-3 and DU145 cells.

Apoptosis is induced through cell death extrinsic pathway or through mitochondrial dependent intrinsic pathway[23]. Western blotting assay showed that combination of Tanshinone I $(0,20,40 \mu \mathrm{M})$ and TRAIL (25 ng) activated caspase 8, caspase 9, caspase 3 and cleaved PARP in PC-3 or DU145 cells (Fig 2C). Furthermore, combination of Tanshinone I and TRAIL suppressed the expression of pro-survival genes such as $\mathrm{Bcl}-\mathrm{X}_{\mathrm{L}}$ and $\mathrm{Bcl}-2$ (Fig 2C) and also attenuated phosphorylation of extracellular signal regulated kinases (ERK), but did not affect p-AKT in PC-3 cells (Fig 2D). In addition, ROS level was determined in PC-3 and DU 145 cells by combination of TRAIL and/or Tanshinone I by fluorescent 2',7'-dichlorofluorescein (DCF) methods. As shown in Fig 2E, Tanshinone I and TRAIL combination increased the level of ROS in PC-3 and DU 145 cells.

\section{Combination of Tanshinone I and TRAIL upregulated DR5 in PC-3 cells}

To understand the apoptotic mechanism of Tanshinone I and TRAIL induced apoptosis, the effect of Tanshinone I and/or TRAIL on the expression of death receptor-related genes such as DR5 or DR4 was evaluated in PC-3 or DU145 cells. As shown in Fig 3A, western blotting showed that combination of Tanshinone I and TRAIL enhanced the expression of DR5 at protein level in PC-3 or DU145 cells, but not DR4. Consistently, combination of Tanshinone I and TRAIL increased the 

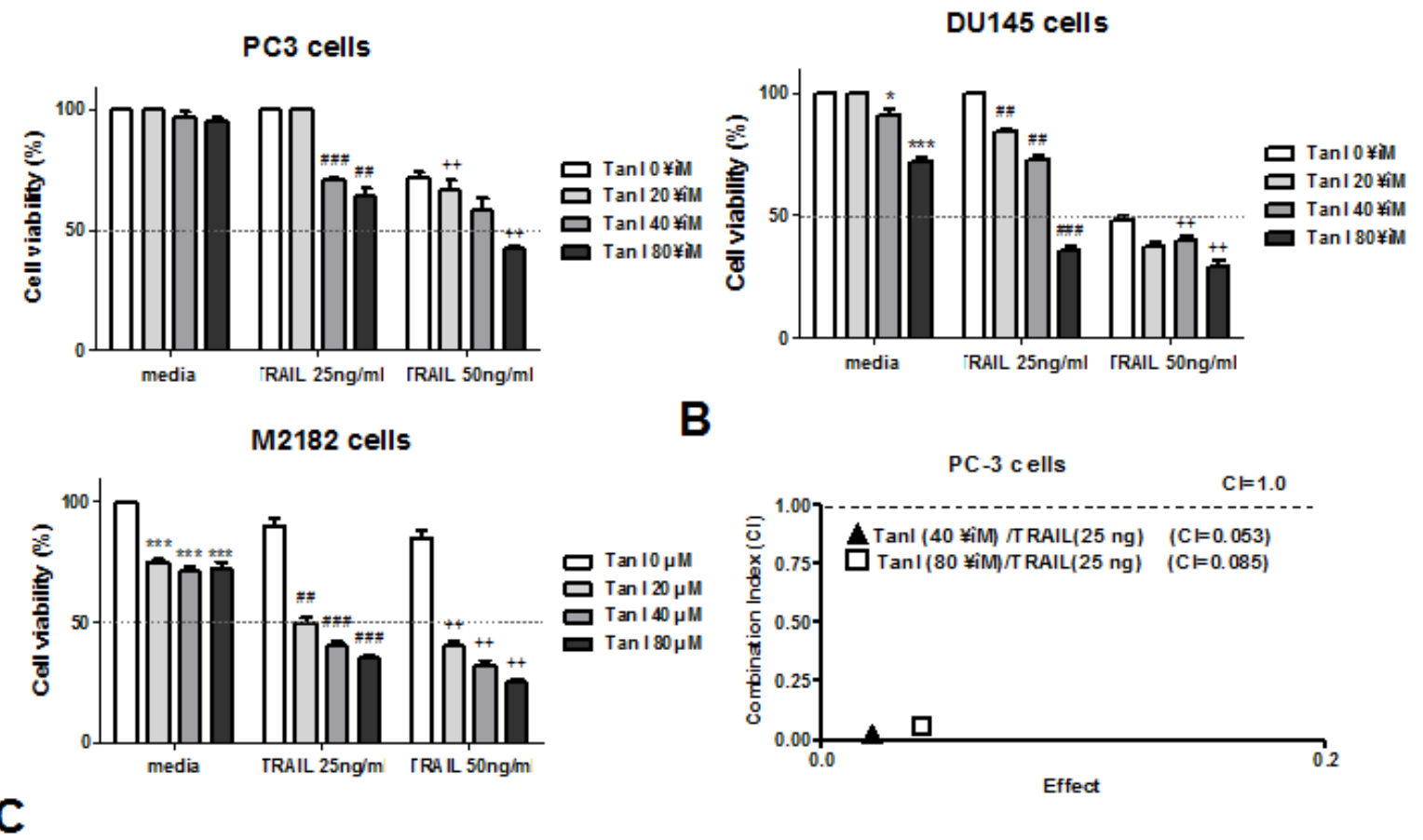

PC-3 cells

TRAIL(25ng/ml)

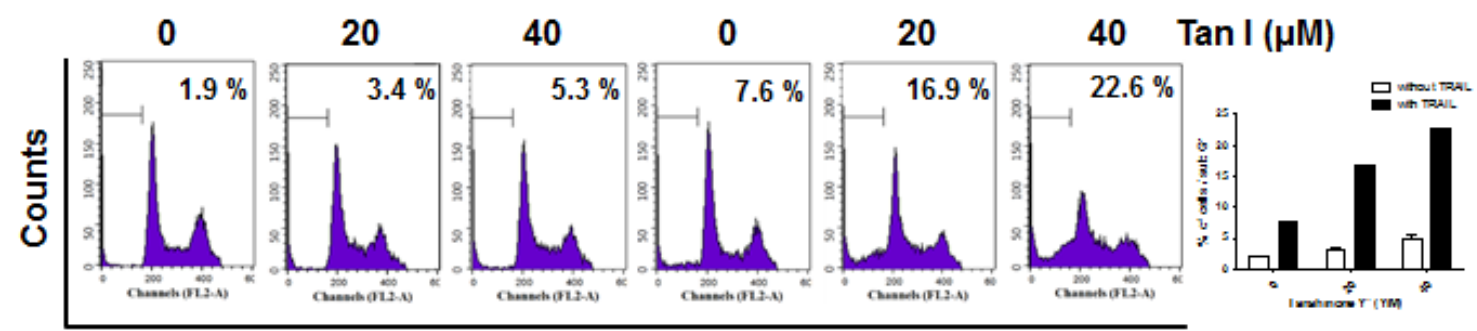

DNA content

DU145 cells

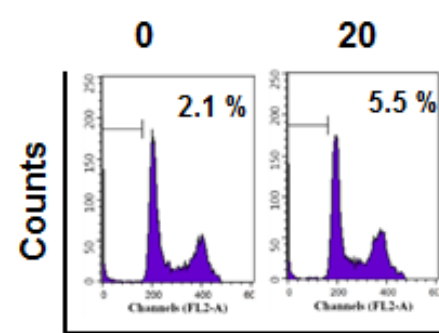

TRAIL(25ng/ml)

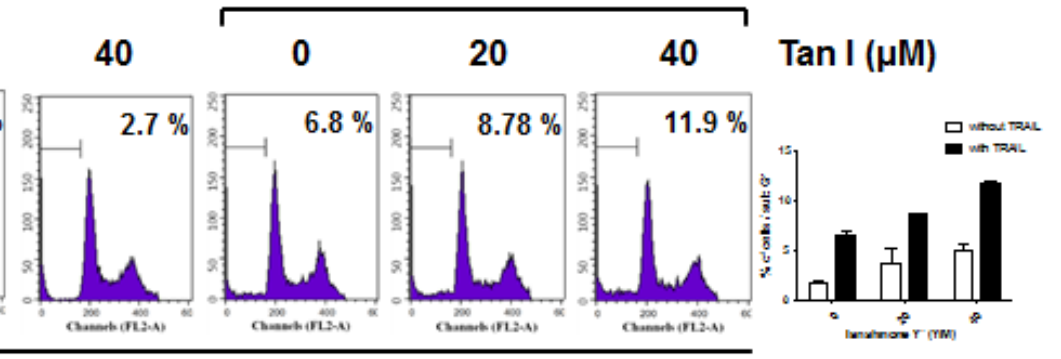

DNA content

Fig 1: Tanshinone I enhances cytotoxicity and sub G1 population of TRAIL in prostate cancer cells. (A) Effect of Tanshinone I on the cytotoxicity of TRAIL in PC-3, DU145 and M2182 cells. Three human prostate cancer cell lines were seeded onto 96-well microplates at a density of $1 \times 10^{4}$ cells/well and treated with various concentration of Tanshinone I (Tan 1; 0, 20,40,80 $\mu \mathrm{M}$ ) and/ or TRAIL ( 25 or $50 \mathrm{ng} / \mathrm{ml}$ ) for $24 \mathrm{~h}$. Cell viability was determined by MTT assay. ${ }^{*} \mathrm{p}<0.05, * * * \mathrm{p}<0.001$ vs untreated control, \#\# $\mathrm{p}<0.01$, $\# \# \# \mathrm{p}<0.001$ vs TRAIL $25 \mathrm{ng}$ treated control, $++\mathrm{p}<0.01$ vs TRAIL 50ng treated control. Data are presented as means \pm SEM of triplicate samples. (B) The combination index (CI) between Tan I and TRAIL was determined by Chou-Talalay method and CalcuSyn software. (C) Effect of Tanshinone I on sub G1 accumulation of TRAIL in PC-3 and DU145 cells. Flow cytometric analysis for sub-G1 apoptotic portion in PC-3 and DU145 cells. PC-3 and DU145 cells were treated with $25 \mathrm{ng} / \mathrm{ml}$ TRAIL in the absence or presence of Tan I (20, $40 \mu \mathrm{M})$ for 24 h. Graphs represent percentages of subG1 portion. Data are presented as means \pm SEM of triplicate samples. 
mRNA expression of DR5 by RT-PCR (Fig 3B) or RTqPCR (Fig 3C) in PC-3 or DU145 cells. To confirm the effect of Tanshinone I and TRAIL on DR5 gene expression, luciferase gene assay was performed. PC-3 cells were transfected with pDR5/-605 promoter and then treated with Tanshinone I and/or TRAIL. Combination of TRAIL and Tanshinone I increased DR5 promoter activity compared to untreated control or TRAIL alone (Fig 3D). Furthermore, FACS analysis for the cell surface expression of DR5 showed that cell surface expression of DR5 was much more detected in Tanshinone I and TRAIL treated PC-3 cells compared to untreated control (Fig 3E).

\section{Silencing of DR5 suppressed the ability of Tanshinone I and TRAIL combination to enhance cytotoxicity, PARP cleavage and sub G1 population $\mathrm{PC}-3$ cells.}

To determine whether upregulation of DR5 plays a critical role in sensitization of PC-3 cells to TRAIL, control or DR5 siRNA plasmids transfected PC-3 cells were treated with Tanshinone I and/or TRAIL. As shown in Fig 4A, silencing of DR5 suppressed cytotoxicity induced by combination of Tanshinone I and TRAIL, while combination of Tanshinone I and TRAIL exerted dose dependent cytotoxicity in control vector treated PC-3 cells by MTT assay (Fig 4A). Similarly, silencing of DR5 attenuated the cleavage of PARP (Fig 4B) and also reduced sub G1 population up to $20.1 \%$ from apoptotic portion (45.2\%) exerted (Fig 4C) by combination of Tanshinone I and TRAIL in PC-3 cells.

\section{Activation of miR135a-3p by combination of Tanshinone I and TRAIL mediated upregulation of DR 5 in PC-3 cells}

MicroRNAs, non-coding RNAs, play an important role in apoptosis $[24,25]$. MicroRNA 135a was known as a selective killer in glioma cancer cells [20] and a tumor suppressor in renal cell carcinoma [19]. We selected the
$\mathbf{A}$

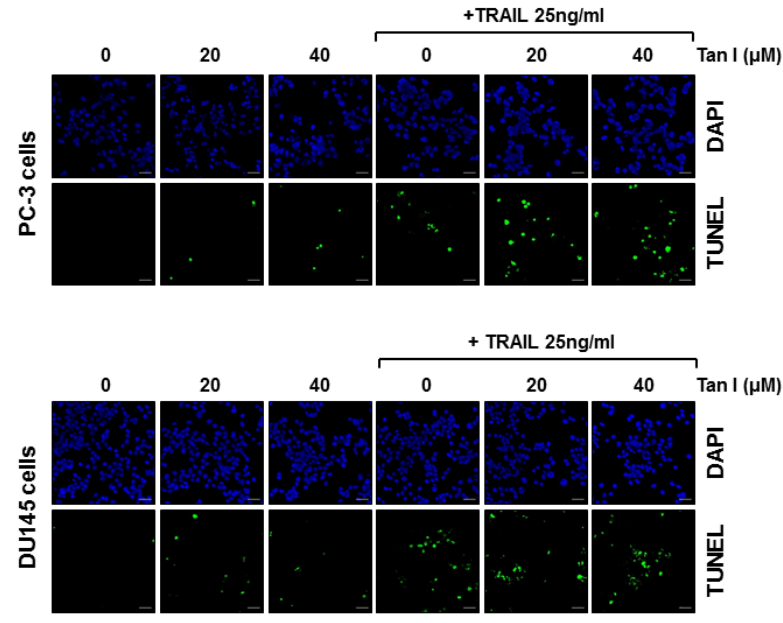

B

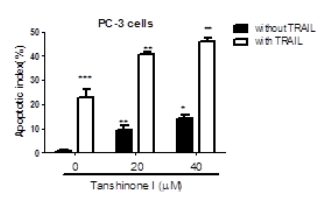

C
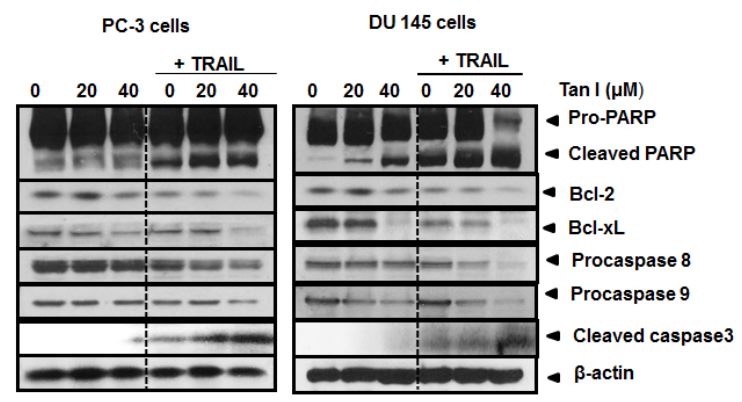

D

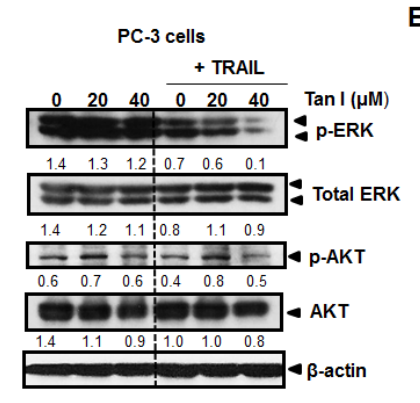

E

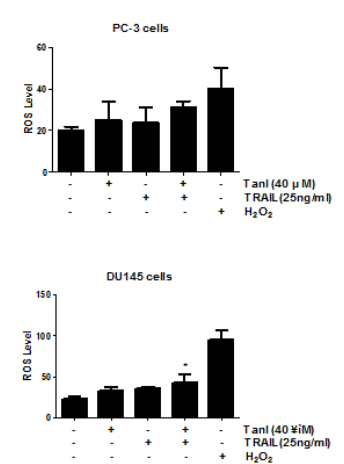

Fig 2: Tanshinone I regulates apoptotic proteins, generates ROS production in TRAIL treated PC-3 cells. (A) Effect of Tanshinone I on the number of TUNEL positive cells in PC-3 and DU145 cells. PC-3 and DU145 cells were treated with Tanshinone I (20, $40 \mu \mathrm{M})$ and/or TRAIL (25 ng), and analyzed by TUNEL assay. The fluorescent signals from fragmented DNA (green), and DAPI (blue) were visualized and photographed by a FLUOVIEW FV10i confocal microscopy. Magnification bar = 50 um. (B) Bar graphs represent quantification of TUNEL positive cells. Data are presented as means \pm SEM of triplicate samples. (C) Effect of Tanshinone I and/or TRAIL on apoptotic proteins in PC-3 and DU145 cells. PC-3 and DU145 cells were treated in the absence or presence of Tanshinone I (20, $40 \mu \mathrm{M})$ and/ or TRAIL ( $25 \mathrm{ng} / \mathrm{ml}$ ) for $24 \mathrm{~h}$. Western blotting was subjected for PARP, procaspase 8, procaspase 9, cleaved caspase3, Bcl-2, Bcl-xL, and $\beta$-Actin was used as the internal control. (D) Effect of Tanshinone I and/or TRAIL on p-ERK and p-AKT signaling in PC-3. Western blotting was subjected for p-ERK, total ERK, p-AKT, AKT and $\beta$-Actin. Values represent the relative expression of each genes normalized to $\beta$ - actin by using Image $J$ software. (E) Effect of Tanshinone I ( $40 \mu \mathrm{M})$ and/or TRAIL (25ng) on ROS production by using microplate fluorometer. Hydrogen peroxide (H2O2) was used as a positive control. Data are presented as means \pm SEM of triplicate samples. ${ }^{*} \mathrm{p}<$ 0.05 . 
A

PC-3 cells

DU145 cells
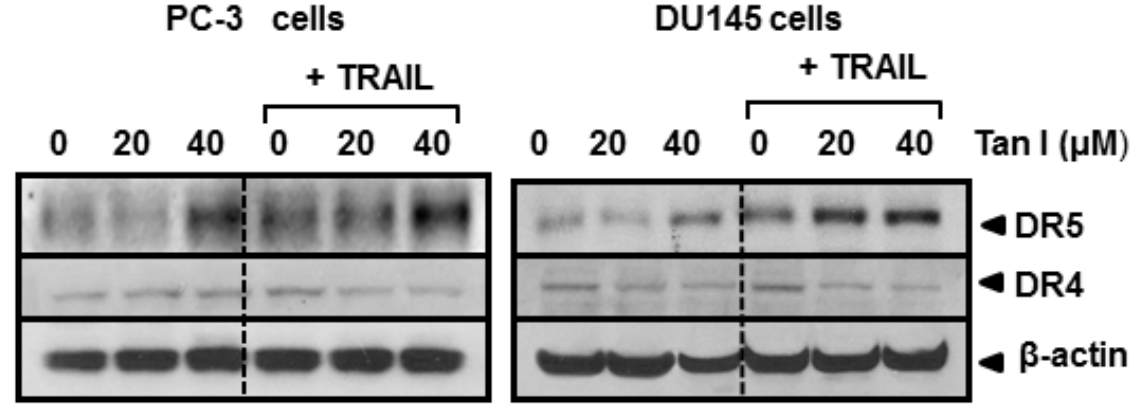

B

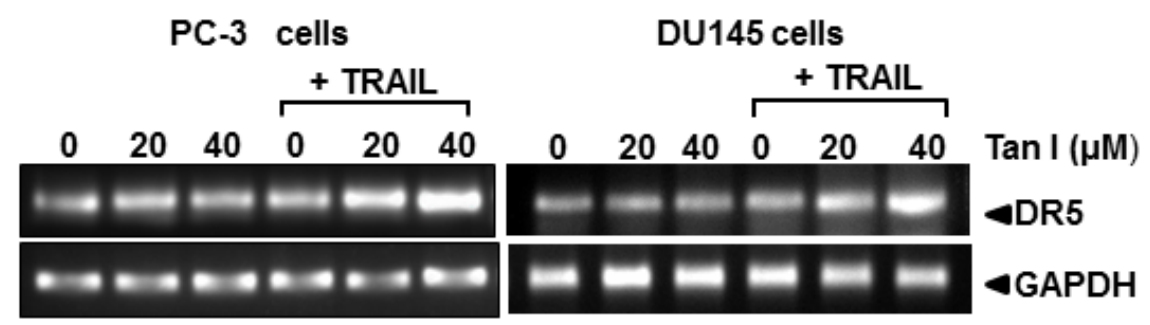

C

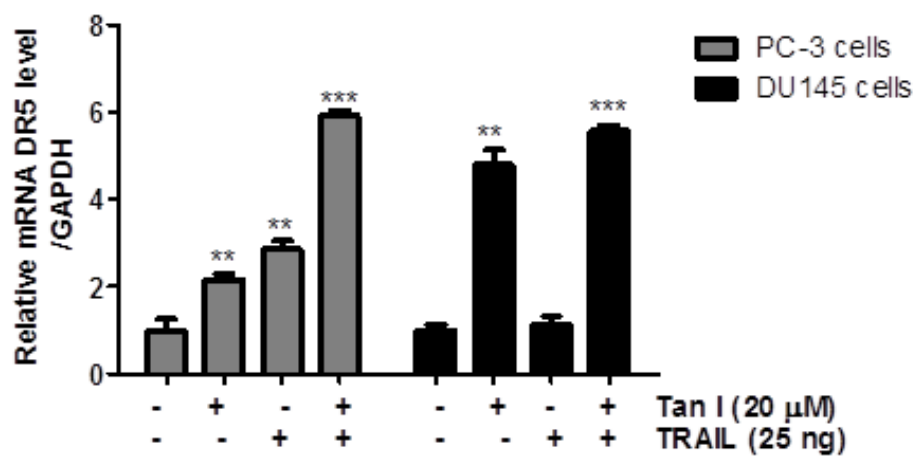

D

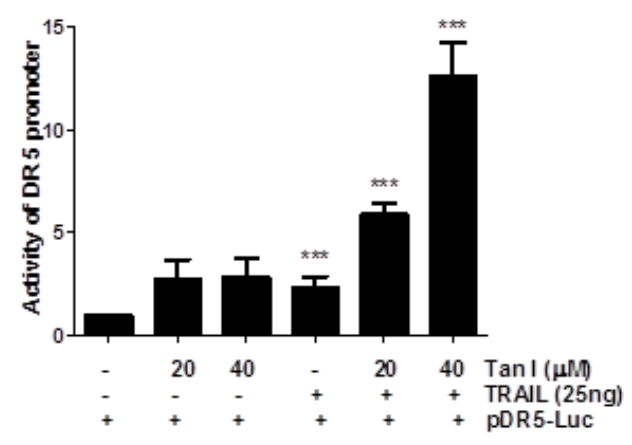

$\mathbf{E}$

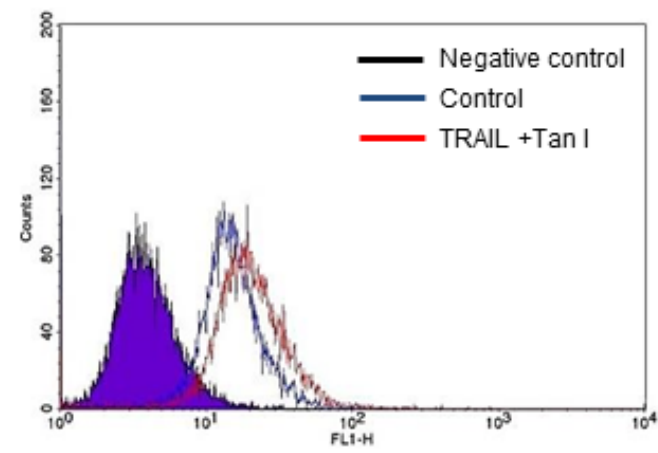

Fig 3: Tanshinone I enhances upregulation of DR5 at mRNA and protein levels, activity of DR5 promoter and cell surface expression of DR5 in PC-3 and DU145 cells. (A) Effect of Tanshinone I on DR4 and DR5 at protein level in TRAIL treated PC-3 and DU145 cells. PC-3 and DU145 cells were treated with Tanshinone I (20, $40 \mu \mathrm{M})$ and/or TRAIL (25ng/ml) for $24 \mathrm{~h}$. Expression levels of DR5 and DR4 were determined by Western blotting. Beta-actin was used as the internal control. The mRNA expression level of DR5 was determined by RT-PCR (B) or RT-qPCR (C) in TRAIL treated PC-3 and DU145 cells. ** p<0.01, *** p<0.001 vs untreated control. (D) Effect of Tanshinone I on activity of DR5 promoter in TRAIL treated PC-3 cells. DR5 promoter plasmid and renilla were transfected into PC-3 cells and incubated for $24 \mathrm{~h}$. Tanshinone I (20, $40 \mu \mathrm{M})$ and/or TRAIL (20 ng) were added. Luciferase was normalized to renilla luciferase activity. (E) Effect of Tanshinone I on cell surface expression of DR5 in TRAIL treated PC-3 cells by Flow cytometry. Tan I (40 $\mu \mathrm{M})$ and TRAIL (25 ng) treated PC-3 cells were stained with DR5-FITC conjugated antibody and control IgG (negative control) and analyzed by Flow cytometric analysis. 
miR135a for TRAIL combination study among many microRNAs, since bioinformatics analysis through microRNA.org predicted that the binding site of miR135a was at the 3'-UTR of DR5 mRNA. In the current study, we checked whether miR135a-3p mediates apoptosis induced by combination of TRAIL and Tanshinone I in PC-3 cells. Here, the expression of miR135a-3p was upregulated by combination of Tanshinone I and TRAIL in PC-3 cells (Fig 5A). Furthermore, overexpression of miR135a-3p enhanced upregulation of DR5 at mRNA or protein level by RT-qPCR (Fig 5B), RT-PCR and Western blotting (Fig 5C).

Overexpression of miR135a-3p promoted cytotoxicity, sub G1 accumulation and PARP cleavage in Tanshinone I and TRAIL I cotreated PC-3 cells

To investigate the role of $\operatorname{miR} 135 \mathrm{a}-3 \mathrm{p}$ in cytotoxicity and apoptosis induced by Tanshinone I and/ or TRAIL in PC-3 or DU145 cells, miR135a-3p mimic

A

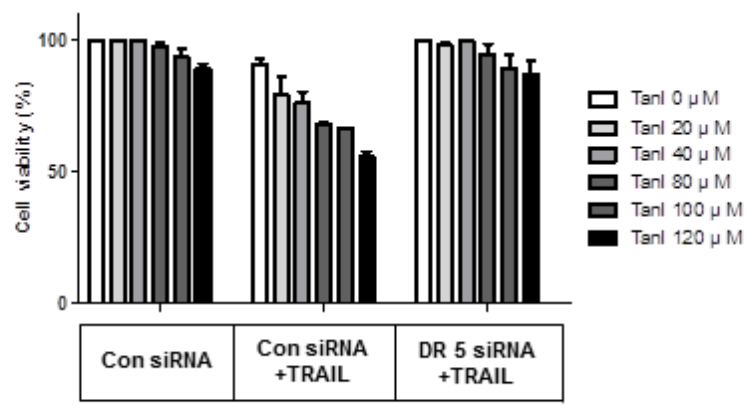

B

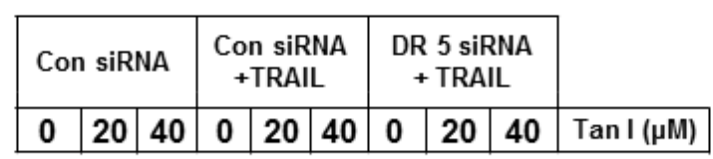

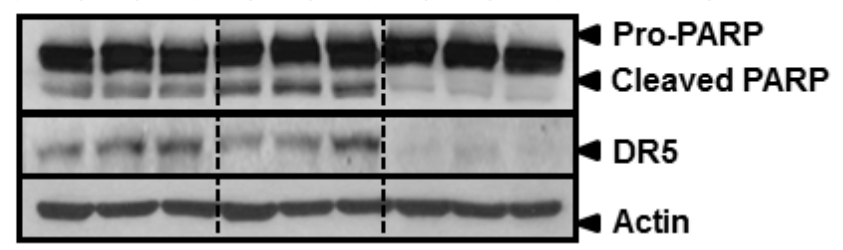

C

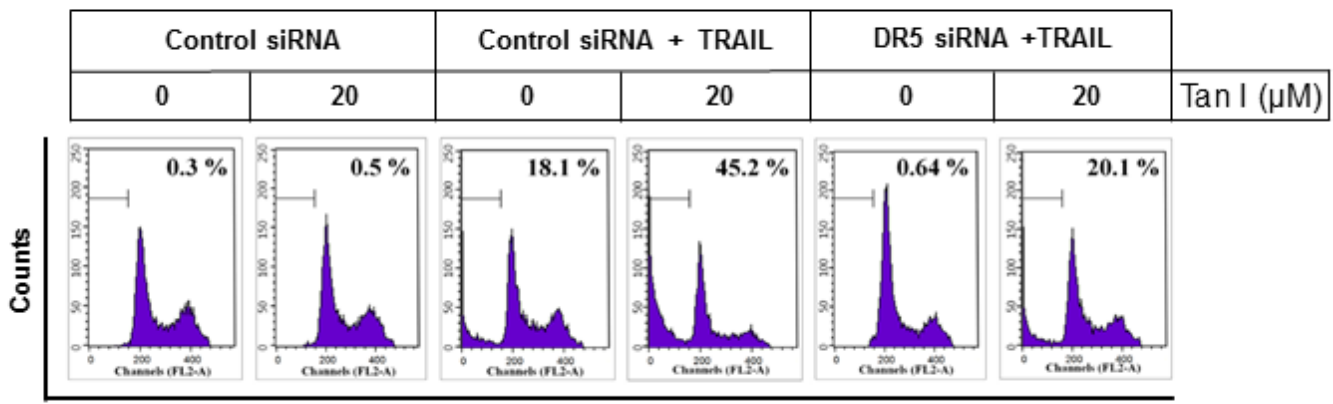

DNA content

Fig 4: Silencing of DR 5 suppresses cell death induced by Tanshinone I and TRAIL in PC-3 cells. PC-3 cells were transfected with control or DR5 siRNA plasmids for $48 \mathrm{~h}$ and then treated with various concentration of Tanshinone I $(0,20,40,80,100$, $120 \mu \mathrm{M})$ and/or TRAIL ( $25 \mathrm{ng} / \mathrm{ml}$ ) for $24 \mathrm{~h}$. (A) Effect of DR5 knockdown on the cytotoxicity by combination of Tanshinone I and TRAIL in PC-3 cells by MTT assay. (B) Effect of DR5 knockdown on PARP cleavage and DR5 induced by combination of Tanshinone I and TRAIL in PC-3 cells. Western blot analysis was performed to determine PARP cleavage and DR5 using Actin as an internal control. (C) Effect of DR5 knockdown on increased sub-G1 population by combination of Tanshinone I and TRAIL in PC-3 cells. Flow cytometric analysis was performed for sub-G1 population in DR5 siRNA plasmid transfected PC-3 cells after exposure to combination of Tanshinone I and TRAIL for $24 \mathrm{~h}$. 
was transfected into PC-3 and DU145 cells and also exposed to Tanshinone I and/or TRAIL. As shown in Fig 6A, miR135a-3p mimic enhanced cytotoxicity by combination with Tanshinone I and TRAIL in PC-3 or DU145 cells compared to Tanshinone I or TRAIL alone. Likewise, we also confirmed that miR135a-3p mimic promoted sub G1 accumulation (34.07\%) induced by combination of Tanshinone I and TRAIL in PC-3 cells compared to Tanshinone I and TRAIL cotreated control (26.52\%), while miR135a-3p inhibitor decreased sub G1 accumulation to $20.36 \%$ (Fig 6B). Also, as shown in Fig $6 \mathrm{C}$, TUNEL assay showed that the numbers of TUNEL positive cells were increased in Tanshinone I and TRAIL cotreated PC-3 cells by miR $135 \mathrm{a}-3 \mathrm{p}$ mimic transfection. Consistently, Western blotting revealed that cleaved PARP and BAX by combination of Tanshinone I and TRAIL were enhanced in miR135a-3p mimic transfected PC-3 cells (Fig 6D).

\section{DISCUSSION}

Though TRAIL has been considered as a potent anticancer agent in several cancers such as colon [6], prostate [26-28], breast [29, 30], bladder and kidney cancers $[31,32]$, its resistance during cancer therapy is a hot issue to overcome. Thus, recently several natural compounds such as quercetin [33], curcumin [34], artepillin C [35], azadirone [36], emetine [37], crytotanshinone [38] and salirasib [39] are attractive as TRAIL sensitizers in many cancers. In the current study, we provide evidences that Tanshinone I sensitizes the prostate cancer cells to TRAIL induced apoptosis via upregulation of miR 135a-3p mediated DR5.

Combination of Tanshinone I and TRAIL showed synergistic cytotoxicity in PC-3, DU145 and M2182 prostate cancer cells compared to Tanshinone I or TRAIL alone, indicating the potential of Tanshinone I as a TRAIL sensitizer. Also, combination of Tanshinone I and TRAIL

\section{B}

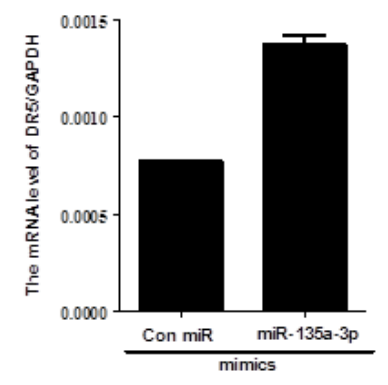

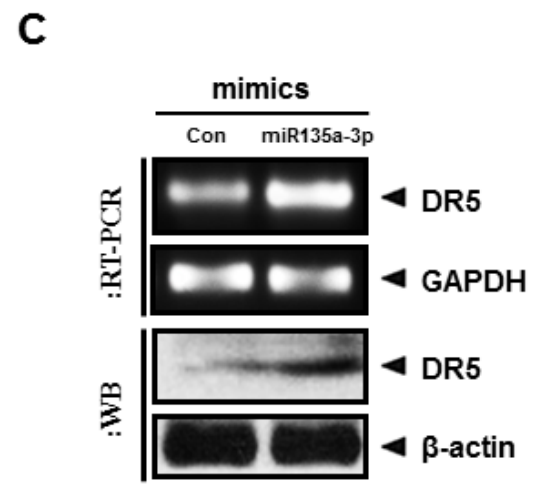

Fig 5: Overexpression of miR135a-3p enhanced sub G1 accumulation and DR5 upregulation at mRNA and protein levels in PC-3 cells. (A) Effect of Tanshinone I and TRAIL combination on mRNA level of miR135a-3p in PC-3 cells by RT-qPCR. The expression level of miR135a-3p by combination of Tanshinone I (20, $40 \mu \mathrm{M})$ and/ or TRAIL (25ng) was evaluated in PC-3 cells by RT-qPCR. After treatment of Tanshinone I and /or TRAIL in PC-3 cells for $24 \mathrm{~h}, \mathrm{RT}-\mathrm{qPCR}$ was performed with total RNA isolated from PC-3 cells to check the mRNA level of miR135a-3p. (B-C) Effect of miR135a-3p mimics on DR5 at mRNA and protein levels in PC-3 by RT-qPCR (B), RT-PCR (C, upper panel) and Western blotting (C, lower panel). 
A

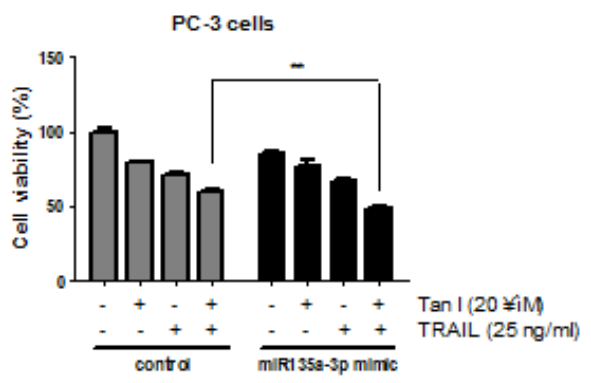

B

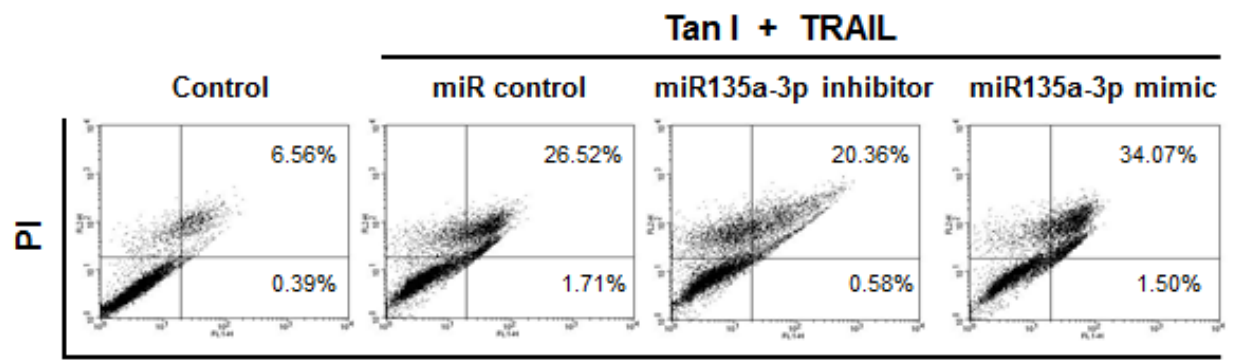

Annexin V-FITC

C

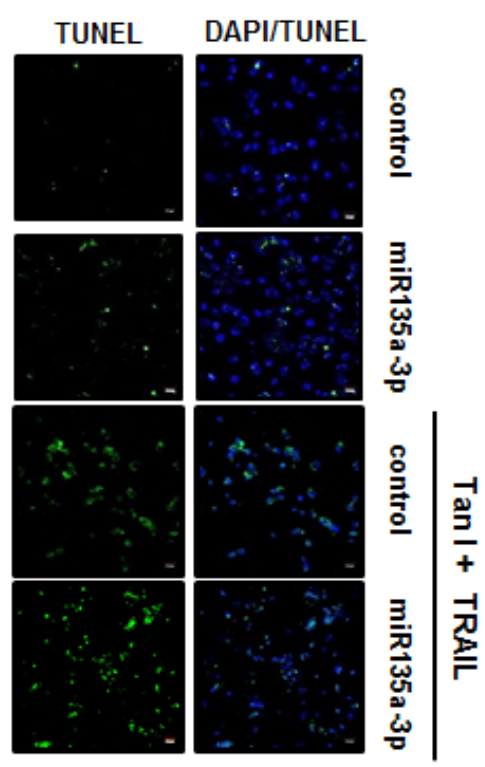

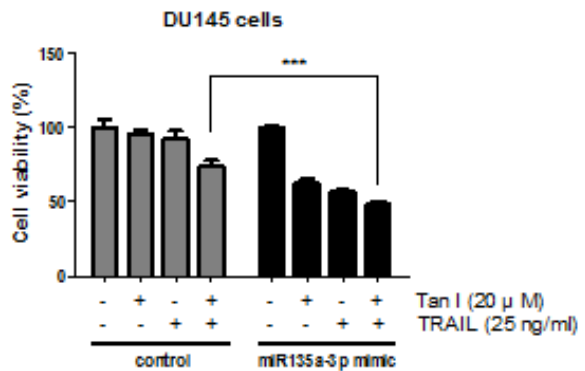

miR $135 a \hat{p} \mathrm{pmimc}$

\section{D}

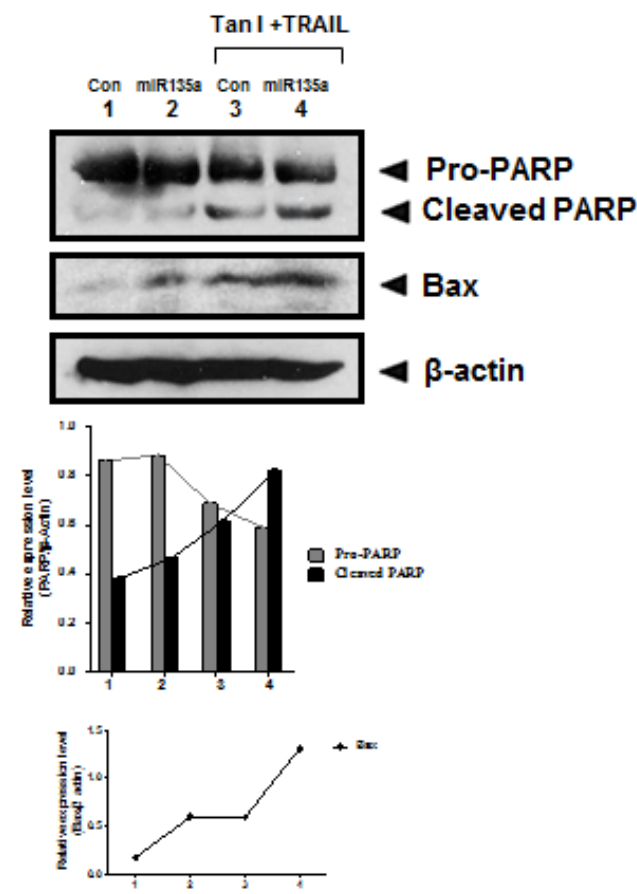

Fig 6: Overexpression of miR135a-3p enhanced cytotoxicity, sub G1 population, the number of TUNEL positive cells, PARP cleavage and Bax in Tanshinone I and TRAIL treated prostate cancer cells. (A) Effect of miR135-3p mimics on the cytotoxicity in PC-3 and DU145 cells. Control and miR135-3p mimic plasmids were transfected into PC-3 or DU145 cells for 48 h, and then exposed to Tanshinone I and/or TRAIL for $24 \mathrm{~h}$. Cell viability was determined by MTT assay. $* * p<0.01, * * * p<0.001$ vs combination of Tanshinone I and TRAIL in control. Data are presented as means \pm SEM of triplicate samples. (B) Effect of miR135-3p mimics on sub G1 population in PC-3 cells. PC-3 cells transfected with miR135a-3p mimics or inhibitor in the absence or presence of Tanshinone I and TRAIL were stained with Annexin V-FITC and PI (Annexin V-FITC apoptosis detection kit, Sigma). Early and late apoptotic portion was determined by Flow cytometric analysis (FACS analyzer). (C) Effect of miR135-3p mimics on the number of TUNEL positive cells in Tanshinone I and/or TRAIL treated PC-3 cells by TUNEL assay. (D) Effect of miR135-3p mimics on PARP cleavage and Bax in Tanshinone I and/or TRAIL treated PC-3 cells by Western blotting. Bar graphs represent the relative expression of PARP or Bax to $\beta$ - actin by using Image J software. 
cleaved PARP, activated caspase $8 / 9$, and increased sub G1 population and the number of TUNEL positive cells as apoptotic features in PC-3 and DU145 cells, implying that the cytotoxicity of Tanshinone I and TRAIL was induced by apoptosis induction via caspase activation and sub G1 apoptotic portion accumulation.

It is well known that apoptosis is induced via two typical apoptotic pathways such as mitochondrial dependent intrinsic pathway and cell death receptor dependent extrinsic pathway in cancers [40-42]. Also, there are accumulating evidences that overexpression of cell survival or anti-apoptotic proteins such as Bcl-2, and Bcl-xL contributes to TRAIL resistance in cancer cells [43] and TRAIL induces apoptosis by binding to its cell surface death receptors such as DR4 and DR5 [44]. In this regard, our western blotting showed that combination of Tanshinone I and TRAIL attenuated the anti-apoptotic proteins such as Bcl-2, Bcl- ${ }_{\mathrm{X}} \mathrm{L}$ and also activated caspase 8, 9 and DR5 in PC-3 and DU145 cells. We also confirmed the upregulation of DR5 in PC-3 cells by combination of

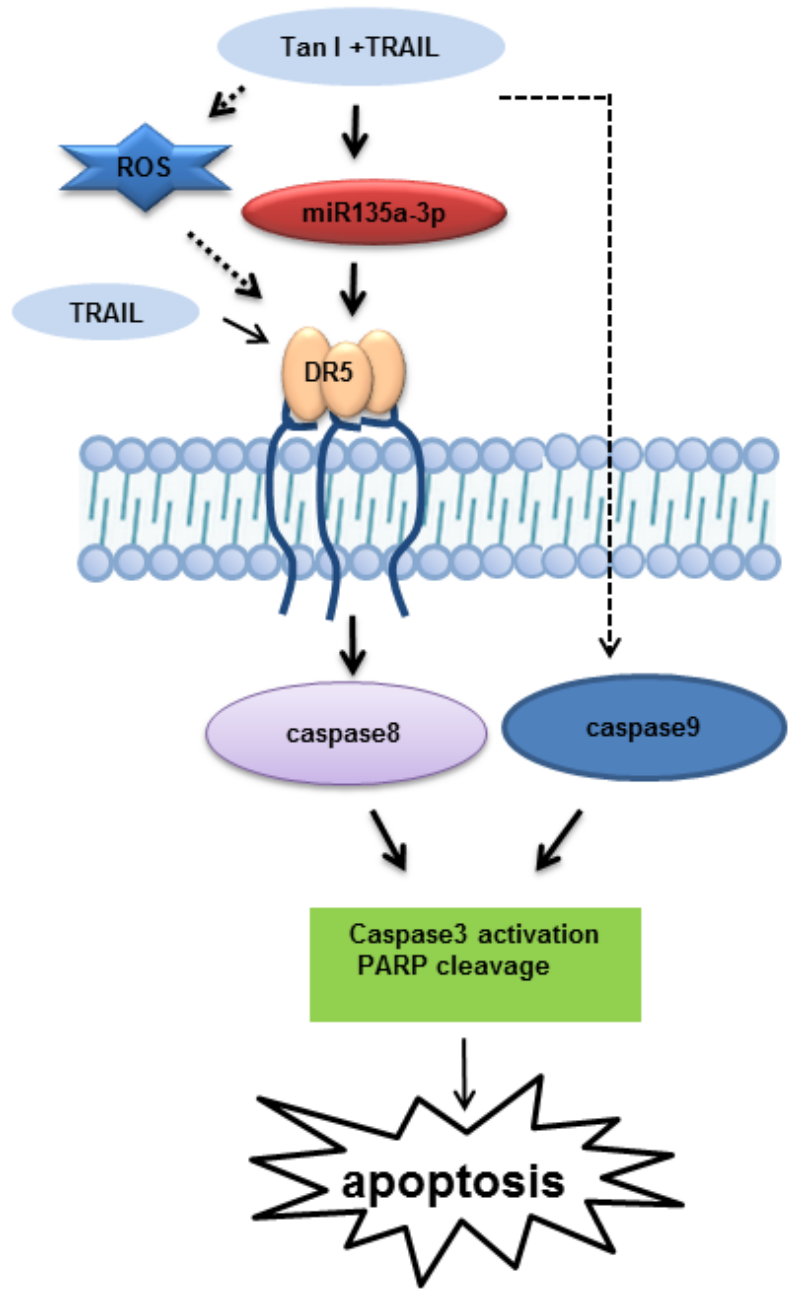

Fig 7: A schematic representation of the signaling pathway affected by combination of Tanshinone I and TRAIL in prostate cancer cells.
Tanshinone I and TRAIL by promoter assay and FACS analysis for cell surface DR5 expression, demonstrating that Tanshinone I can sensitize prostate cancer cells to TRAIL induced apoptosis via upregulation of DR5 and suppression of survival genes. Conversely, the silencing of DR5 blocked the increased cytotoxicity and sub G1 population and PARP cleavages induced by co-treatment of Tanshinone I and TRAIL in PC-3 cells.

It is well documented that TRAIL induces apoptosis via microRNA regulation [45] including miR34a/ [46] or miR-494 [47] in cancer cells. Thus, Farooqi et al [3] suggested that miRNA regulation of TRAIL-mediated signaling in prostate cancer cells can provide potential biomarkers for the characterization of patients as responders and non-responders for TRAIL-based therapy. Recently, miR-135a was also reported to inhibit the proliferation of renal carcinoma [19], induce apoptosis in gastric cancer cells [48] and promote drug sensitivity in cancer cells[49]. Our RT-PCR and RT-qPCR analyses confirmed that combination of Tanshinone I and TRAIL up-regulated miR135a-3p and DR5 at mRNA level or activity of DR5 promoter in PC-3 cells, indicating the possible involvement of miR135a-3p along with DR5 upregulation in antitumor activity of Tanshinone I and TRAIL in PC-3 cells.

Of note, overexpression of miR $135 a-3 p$ using its mimic plasmids enhanced the ability of Tanshinone I and TRAIL combination to promote cytotoxicity, upregulate DR5 at mRNA, cleaved PARP and increase the number of TUNEL positive cells in PC-3 cells compared to untreated control, implying that miR135a-3p plays a pivotal role in apoptotic activity by combination of Tanshinone I and TRAIL in PC-3 and DU145 cells.

Collectively, our results demonstrate that combination of Tanshinone I and TRAIL synergistically induce apoptosis via upregulation of miR135a-3p and DR5 in prostate cancer cells and overexpression of miR135a$3 p$ enhances upregulation of DR5 leading to cell death by combined treatment of TRAIL and Tanshinone I. Thus, our findings suggest that Tanshinone I can be used as a potent sensitizer for TRAIL-based combination therapy in prostate cancer cells.

\section{METHODS}

\section{Cell culture}

PC-3, M2182 and DU145 cells (human prostate cancer cells) were purchased from American Type Culture Collection (ATCC, Manassas, USA). The cells were cultured in RPMI1640 medium supplemented with $10 \%$ fetal bovine serum (FBS), $2 \mu \mathrm{M}$ L-glutamine and penicillin/streptomycin of $5 \% \mathrm{CO}_{2}$ at $37^{\circ} \mathrm{C}$. 


\section{Cytotoxicity assay}

The cytotoxic effect of Tanshinone I and/or TRAIL against PC-3 , M2182, or DU145 cells was evaluated by using 3-(4, 5-dimethylthiazol-2-yl)-2,5diphenyltetrazolium bromide (MTT) assay (Sigma, St. Louis, MO, USA) according to the manufacturer's instruction. Briefly, prostate cancer cells were seeded onto 96-well microplate and treated with various concentrations of Tanshinone I $(0,20,40$ or $80 \mu \mathrm{M})$ (Sigma, St. Louis, MO, USA) and/or TRAIL (25 or $50 \mathrm{ng}$ ) (Sigma, St. Louis, MO, USA) for $24 \mathrm{~h}$. MTT solution ( $5 \mathrm{mg} / \mathrm{ml})$ was added and formazan was dissolved with MTT lysis solution ( $20 \%$ SDS and $50 \%$ dimethylformamide). To measure the optical density, microplate reader (TECAN, Austria) at $450 \mathrm{~nm}$ was used. Cell viability was determined as a percentage of viable cells in Tanshinone I and/or TRAIL treated group versus untreated control.

\section{Cell cycle analysis}

PC-3 or DU145 cells were treated with Tanshinone I and/or TRAIL for $24 \mathrm{~h}$ and fixed in $75 \%$ ethanol. Fixed cells were resuspended in PBS containing RNase A ( $1 \mathrm{mg} /$ $\mathrm{ml}$ ), and incubated for $1 \mathrm{~h}$ at $37^{\circ} \mathrm{C}$. After incubation, fixed cells were stained with propidium iodide $(50 \mu \mathrm{g} / \mathrm{ml})$ for $30 \mathrm{~min}$ at room temperature in dark for sub G1 population and also for early and late apoptosis, Annexin-V FITC/ propidium iodide double staining was performed according to the manufacturer's instruction. To analyze the DNA contents of the stained cells, CellQuest Software with the FACSCalibur flow cytometry was used (Becton Dickinson, Franklin Lakes, NJ).

\section{TUNEL Assay}

To detect cell death, the DeadEndTM Fluorometric terminal deoxynucleotidyl transferase-mediated dUTPbiotin nick end labeling (TUNEL) system kit was used according to the manufacturer's instructions (Sigma, St. Louis, MO, USA). In brief, DU145 or PC-3 cells treated with Tanshinone I and/or TRAIL for $24 \mathrm{~h}$ were washed with cold PBS. Cells were fixed with $4 \%$ paraformaldehyde for $30 \mathrm{~min}$ and washed twice with PBS for 2 min. Fixed cells in permeabilization solution ( $0.1 \%$ Triton X-100 and $0.1 \%$ Sodium citrate) were washed and incubated with TUNEL assay mixture for $60 \mathrm{~min}$. The TUNEL-stained cells were visualized by a FLUOVIEW FV10i confocal microscopy (Olympus, Tokyo, Japan).

\section{RT-PCR and RT-qPCR analyses}

Total RNA from prostate cells was isolated using the QIAzol (Invitrogen, Carlsbad, CA, USA) and one microgram of total RNA was used to make cDNA by Superscript reverse transcriptase and amplified by Platinum Taq polymerase with Superscript One Step RT-PCR kit (Invitrogen, Carsbad, CA,USA). Primers sequences used were synthesized by Bioneer (Daejeon, Korea) with the following sequences: hDR5-forwad-5'GTC TGC TCT GAT CAC CCA AC-3', reverse-5'-CTG CAA ACT GTG ACT CCT ATG-3', hGAPDH -forward - 5'-TCA CCA TCT TCC AGG AGC GA-3'; reverse -5'-CAC AAT GCC GAA GTG GTG GT-3'. For PCR amplification, following conditions was used ; an initial step at $50{ }^{\circ} \mathrm{C}$ for $30 \mathrm{~min}, 94^{\circ} \mathrm{C}$ for $2 \mathrm{~min}$, followed by 30 cycles at $94^{\circ} \mathrm{C}$ for $15 \mathrm{~s}, 55^{\circ} \mathrm{C}$ for $30 \mathrm{~s}$ and $72^{\circ} \mathrm{C}$ for $1 \mathrm{~min}$, and a final step at $72^{\circ} \mathrm{C}$ for $10 \mathrm{~min}$. The amplified products were separated on $2 \%$ agarose gel. For RT-qPCR, RTqPCR was performed with the LightCycler TM instrument (Roche Applied Sciences, Indianapolis, IN) with following primers, hDR5- forward: 5'- GAC TCT GAG ACA GTG CTT CGA TGA -3'; reverse- 5'-CCA TGA GGC CCA ACT TCC T-3', hGAPDH-forward5'-CCA CTC CTC CAC CTT TGA CA-3';reverse-5'-ACC CTG TTG CTG TAG CCA -3'.

\section{Western blot analysis}

PC-3 or DU145 cells treated by TRAIL and/or Tanshinone I were lysed in RIPA buffer $(50 \mathrm{mM}$ Tris$\mathrm{HCl}, \mathrm{pH} 7.4,150 \mathrm{mM} \mathrm{NaCl}, 1 \% \mathrm{NP}-40,0.25 \%$ sodium deoxycholic acid, $1 \mathrm{M}$ EDTA, $1 \mathrm{mM} \mathrm{Na}_{3} \mathrm{VO}_{4}, 1 \mathrm{mM} \mathrm{NaF}$ and protease inhibitors cocktail). To quantify protein samples, Bio-Rad DC protein assay kit II (Bio-Rad, Hercules, CA, USA) was used. Proteins samples were separated by electrophoresis on SDS-PAGE gel and electrotransferred onto a Hybond ECL transfer membrane (Amersham Pharmacia, Piscataway, NJ, USA). After blocking, the membrane was incubated with primary antibodies for PARP,caspase8, caspase 9, AKT, p-AKT, ERK, pERK, cleaved caspase 3, Bcl-X $\mathrm{X}_{\mathrm{L}} \mathrm{Bcl}$ 2, Bax, DR5 and beta actin (Cell signaling, Beverly, MA,USA) followed by exposing to horseradish peroxidase (HRP)conjugated secondary anti-mouse or rabbit antibodies (AbD serotec, kidlington, UK). To visualize protein bands, chemiluminescence (ECL) system (Amersham Pharmacia, Piscataway, NJ, USA) was used.

\section{Short interfering RNA (siRNA) transfection assay}

PC-3 cells were transiently transfected with control siRNA, or DR5 siRNA (Bioneer, Korea) by using Interferin $^{\mathrm{TM}}$ transfection reagent (Polyplus-transfection Inc., New York, NY). Briefly, the mixture of DR5 siRNA $(40 \mathrm{nM})$ and Interferin ${ }^{\mathrm{TM}}$ transfection reagent was incubated for $10 \mathrm{~min}$, and added to the cells. The cells were incubated at $37^{\circ} \mathrm{C}$ for $48 \mathrm{~h}$ and treated with Tanshinone I and/or TRAIL or for $24 \mathrm{~h}$. 


\section{DR5 promoter assay}

pDR5/-605 promoter construct (gifted from Dr. TK Kwon, Keimyung University, Korea) was transfected into PC-3 cells along with Renilla luciferase reporter plasmid. After $24 \mathrm{~h}$ transfection, the cells were treated with Tanshinone I and/or TRAIL for $24 \mathrm{~h}$. Luciferase activity was measured using Dual-Luciferase Reporter Assay System (Promega, Madison, WI, USA).

\section{FACS analysis for cell surface expression of DR5}

To determine the surface expression of the DR5, FACS analysis was carried out. PC-3 cells treated with Tanshinone I and/or TRAIL for $24 \mathrm{~h}$ were twice washed with PBS and incubated with $10 \mu \mathrm{g} / \mathrm{ml}$ DR5-FITC conjugated or mouse IgG antibody (Abcam, United Kingdom) in PBS for $1 \mathrm{~h}$ at $4^{\circ} \mathrm{C}$. After washing, cells were analyzed by flow cytometry using a FACS Calibur flow cytometer (Becton Dickinson, Franklin Lakes, NJ).

\section{Measurement of reactive oxygen species (ROS) production}

PC-3 or DU145 cells were cultured and then preincubated with dichloro-dihydro-fluorescein diacetate (DCFH-DA) for $1 \mathrm{~h}$ at $37^{\circ} \mathrm{C}$. After incubation, DCFH-DA added cells were treated with Tanshinone I and/or TRAIL for $1 \mathrm{~h}$ at $37^{\circ} \mathrm{C}$. To measure intracellular levels of ROS, the concentration of fluorescent 2', 7'-dichlorofluorescein (DCF) was quantified in oxiselect intracellular ROS assay kits (Cell Biolabs, CA, USA) using Fluoroskan Ascent microplate fluorometer (Thomas scientific, NJ, USA).

\section{MicroRNA (miR) transfection assay}

miR135a-3p or control mimic plasmid (200 nM) (Genolution, Korea) was transfected into PC-3 cells using lipofetamine 2000 (Invitrogen, Carlsbad, CA, USA) reagent according to the manufacture's protocol. To evaluate the expression of miR135a-3p, total RNA from PC-3 cells treated by Tanshinone I and/or TRAIL was isolated by QIAzol (Invitrogen). To construct microRNA cDNA, GenoExplorer ${ }^{\mathrm{TM}}$ miRNA cDNA kit (GenoSensor Corporation, Arizona, USA) was used according to the manufacture's protocol. To measure the level of microRNA, RT-qPCR analysis was performed with the LightCycler TM instrument (Roche Applied Sciences, Indianapolis, IN). MicroRNA primers were purchased from GenoExplorer ${ }^{\mathrm{TM}}$ (GenoSensor Corporation, Arizona, USA) and U6 primer was used to normalized the level of microRNAs.

\section{Combination Index (CI) Calculation}

The combination index was performed by ChouTalalay method and CalcuSyn software (Biosoft, Ferguson, MO, USA). A combination index $\mathrm{CI}<1$ was considered synergistic [50].

\section{Statistical analyses}

Statistical analyses of the data were conducted using Sigmaplot version 12 software (Systat Software Inc., San Jose, CA). All data were expressed as means \pm standard error of the mean (SEM). The statistically significant differences between control and treatments were calculated by the Student's $t$-test and one-way ANOVA test .

\section{Conflict of Interest}

The authors have declared that there is no conflict of interest.

\section{ACKNOWLEDGEMENTS}

This work was supported by the National Research Foundation of Korea(NRF) grant funded by the Korea government(MSIP) (No. No. 2012-0005755).

\section{REFERENCES}

1. Siegel R, Naishadham D and Jemal A. Cancer statistics, 2012. CA Cancer J Clin. 2012; 62(1):10-29.

2. Arya M, Bott SR, Shergill IS, Ahmed HU, Williamson M and Patel HR. The metastatic cascade in prostate cancer. Surg Oncol. 2006; 15(3):117-128.

3. Farooqi AA and De Rosa G. TRAIL and microRNAs in the treatment of prostate cancer: therapeutic potential and role of nanotechnology. Appl Microbiol Biotechnol. 2013; 97(20):8849-8857.

4. Pan G, O'Rourke K, Chinnaiyan AM, Gentz R, Ebner R, Ni J and Dixit VM. The receptor for the cytotoxic ligand TRAIL. Science. 1997; 276(5309):111-113.

5. Walczak H, Degli-Esposti MA, Johnson RS, Smolak PJ, Waugh JY, Boiani N, Timour MS, Gerhart MJ, Schooley KA, Smith CA, Goodwin RG and Rauch CT. TRAIL-R2: a novel apoptosis-mediating receptor for TRAIL. EMBO J. 1997; 16(17):5386-5397.

6. Galligan L, Longley DB, McEwan M, Wilson TR, McLaughlin K and Johnston PG. Chemotherapy and TRAIL-mediated colon cancer cell death: the roles of p53, TRAIL receptors, and c-FLIP. Mol Cancer Ther. 2005; 4(12):2026-2036.

7. Vignati S, Codegoni A, Polato F and Broggini M. Trail 
activity in human ovarian cancer cells: potentiation of the action of cytotoxic drugs. Eur J Cancer. 2002; 38(1):177183.

8. Yamanaka T, Shiraki K, Sugimoto K, Ito T, Fujikawa K, Ito M, Takase K, Moriyama M, Nakano T and Suzuki A. Chemotherapeutic agents augment TRAIL-induced apoptosis in human hepatocellular carcinoma cell lines. Hepatology. 2000; 32(3):482-490.

9. Lu T, Shao N and Ji C. Targeting microRNAs to modulate TRAIL-induced apoptosis of cancer cells. Cancer Gene Ther. 2013; 20(1):33-37.

10. Ovcharenko D, Kelnar K, Johnson C, Leng N and Brown D. Genome-scale microRNA and small interfering RNA screens identify small RNA modulators of TRAIL-induced apoptosis pathway. Cancer research. 2007; 67(22):1078210788.

11. Song JY, Luo HM, Li CF, Sun C, Xu J and Chen SL. [Salvia miltiorrhiza as medicinal model plant]. Yao Xue Xue Bao. 2013; 48(7):1099-1106.

12. Woo KS, Yip TW, Chook P, Kwong SK, Szeto CC, Li JK, Yu AW, Cheng WK, Chan TY, Fung KP and Leung PC. Cardiovascular Protective Effects of Adjunctive Alternative Medicine (Salvia miltiorrhiza and Pueraria lobata) in HighRisk Hypertension. Evid Based Complement Alternat Med. 2013; 2013:132912.

13. Chang CC, Lai JS, Tsai CS, Ma SW, Lin JY, Huang LR, $\mathrm{Lu} \mathrm{CH}$, Liao EC and Ho TF. Proapoptotic and TRAILsensitizing constituents isolated from Salvia militiorrhiza (Danshen). J Biosci Bioeng. 2013; 116(4):516-523.

14. Lee CY, Sher HF, Chen HW, Liu CC, Chen CH, Lin CS, Yang PC, Tsay HS and Chen JJ. Anticancer effects of tanshinone I in human non-small cell lung cancer. Mol Cancer Ther. 2008; 7(11):3527-3538.

15. Nizamutdinova IT, Lee GW, Lee JS, Cho MK, Son KH, Jeon SJ, Kang SS, Kim YS, Lee JH, Seo HG, Chang KC and Kim HJ. Tanshinone I suppresses growth and invasion of human breast cancer cells, MDA-MB-231, through regulation of adhesion molecules. Carcinogenesis. 2008; 29(10):1885-1892.

16. Tang X, Tang X, Gal J, Kyprianou N, Zhu H and Tang G. Detection of microRNAs in prostate cancer cells by microRNA array. Methods in molecular biology. 2011; 732:69-88.

17. Zhu KC, Lu JJ, Xu XL and Sun JM. MicroRNAs in androgen-dependent PCa. Frontiers in bioscience. 2013; 18:748-755.

18. Ma S, Chan YP, Kwan PS, Lee TK, Yan M, Tang KH, Ling MT, Vielkind JR, Guan XY and Chan KW. MicroRNA-616 induces androgen-independent growth of prostate cancer cells by suppressing expression of tissue factor pathway inhibitor TFPI-2. Cancer research. 2011; 71(2):583-592.

19. Yamada Y, Hidaka H, Seki N, Yoshino H, Yamasaki T, Itesako T, Nakagawa $\mathrm{M}$ and Enokida $\mathrm{H}$. Tumor-suppressive microRNA-135a inhibits cancer cell proliferation by targeting the c-MYC oncogene in renal cell carcinoma. Cancer Sci. 2012; 104(3):304-312.

20. Wu S, Lin Y, Xu D, Chen J, Shu M, Zhou Y, Zhu W, Su X, Qiu P and Yan G. MiR-135a functions as a selective killer of malignant glioma. Oncogene. 2011; 31(34):3866-3874.

21. Sallman DA, Chen X, Zhong B, Gilvary DL, Zhou J, Wei $\mathrm{S}$ and Djeu JY. Clusterin mediates TRAIL resistance in prostate tumor cells. Molecular cancer therapeutics. 2007; 6(11):2938-2947.

22. Taurin $\mathrm{S}$ and Nehoff $\mathrm{H}$. A novel role for raloxifene nanomicelles in management of castrate resistant prostate cancer. 2014; 2014:323594.

23. Ouyang L, Shi Z, Zhao S, Wang FT, Zhou TT, Liu B and Bao JK. Programmed cell death pathways in cancer: a review of apoptosis, autophagy and programmed necrosis. Cell Prolif. 45(6):487-498.

24. Lynam-Lennon N, Maher SG and Reynolds JV. The roles of microRNA in cancer and apoptosis. Biol Rev Camb Philos Soc. 2009; 84(1):55-71.

25. Wang Y and Lee CG. MicroRNA and cancer--focus on apoptosis. J Cell Mol Med. 2009; 13(1):12-23.

26. Yu R, Mandlekar S, Ruben S, Ni J and Kong AN. Tumor necrosis factor-related apoptosis-inducing ligand-mediated apoptosis in androgen-independent prostate cancer cells. Cancer research. 2000; 60(9):2384-2389.

27. Nesterov A, Ivashchenko Y and Kraft AS. Tumor necrosis factor-related apoptosis-inducing ligand (TRAIL) triggers apoptosis in normal prostate epithelial cells. Oncogene. 2002; 21(7):1135-1140.

28. Van Ophoven A, Ng CP, Patel B, Bonavida B and Belldegrun A. Tumor necrosis factor-related apoptosisinducing ligand (TRAIL) for treatment of prostate cancer: first results and review of the literature. Prostate Cancer Prostatic Dis. 1999; 2(5/6):227-233.

29. Zhang $\mathrm{Y}$, Yoshida $\mathrm{T}$ and Zhang B. TRAIL induces endocytosis of its death receptors in MDA-MB-231 breast cancer cells. Cancer Biol Ther. 2009; 8(10):917-922.

30. Rahman M, Pumphrey JG and Lipkowitz S. The TRAIL to targeted therapy of breast cancer. Adv Cancer Res. 2009; 103:43-73.

31. Voelkel-Johnson C. TRAIL-mediated signaling in prostate, bladder and renal cancer. Nat Rev Urol. 2011; 8(8):417427.

32. Mellier G, Huang S, Shenoy K and Pervaiz S. TRAILing death in cancer. Mol Aspects Med. 2010; 31(1):93-112.

33. Jung YH, Heo J, Lee YJ, Kwon TK and Kim YH. Quercetin enhances TRAIL-induced apoptosis in prostate cancer cells via increased protein stability of death receptor 5 . Life Sci. 2010; 86(9-10):351-357.

34. Deeb D, Xu YX, Jiang H, Gao X, Janakiraman N, Chapman RA and Gautam SC. Curcumin (diferuloyl-methane) enhances tumor necrosis factor-related apoptosis-inducing ligand-induced apoptosis in LNCaP prostate cancer cells. Mol Cancer Ther. 2003; 2(1):95-103. 
35. Szliszka E, Zydowicz G, Mizgala E and Krol W. Artepillin C (3,5-diprenyl-4-hydroxycinnamic acid) sensitizes LNCaP prostate cancer cells to TRAIL-induced apoptosis. Int $\mathbf{J}$ Oncol. 2012; 41(3):818-828.

36. Gupta SC, Francis SK, Nair MS, Mo YY and Aggarwal BB. Azadirone, a limonoid tetranortriterpene, induces death receptors and sensitizes human cancer cells to tumor necrosis factor-related apoptosis-inducing ligand (TRAIL) through a 53 protein-independent mechanism: evidence for the role of the ROS-ERK-CHOP-death receptor pathway. J Biol Chem. 2013; 288(45):32343-32356.

37. Han Y, Park S, Kinyua AW, Andera L, Kim KW and Kim I. Emetine enhances the tumor necrosis factor-related apoptosis-inducing ligand-induced apoptosis of pancreatic cancer cells by downregulation of myeloid cell leukemia sequence-1 protein. Oncol Rep. 2014; 31(1):456-462.

38. Tse AK, Chow KY, Cao HH, Cheng CY, Kwan HY, Yu $\mathrm{H}, \mathrm{Zhu} \mathrm{GY}, \mathrm{Wu}$ YC, Fong WF and Yu ZL. The herbal compound cryptotanshinone restores sensitivity in cancer cells that are resistant to the tumor necrosis factorrelated apoptosis-inducing ligand. J Biol Chem. 2013; 288(41):29923-29933.

39. Charette N, De Saeger C, Horsmans Y, Leclercq I and Starkel P. Salirasib sensitizes hepatocarcinoma cells to TRAIL-induced apoptosis through DR5 and survivindependent mechanisms. Cell Death Dis. 2013; 4:e471.

40. Burz C, Berindan-Neagoe I, Balacescu O and Irimie A. Apoptosis in cancer: key molecular signaling pathways and therapy targets. Acta Oncol. 2009; 48(6):811-821.

41. Pilkington GJ, Parker K and Murray SA. Approaches to mitochondrially mediated cancer therapy. Semin Cancer Biol. 2008; 18(3):226-235.

42. Holland PM. Death receptor agonist therapies for cancer, which is the right TRAIL? Cytokine Growth Factor Rev. 2013; S1359-6101(13)00107-X. doi: 10.1016.

43. Chawla-Sarkar M, Bae SI, Reu FJ, Jacobs BS, Lindner DJ and Borden EC. Downregulation of Bcl-2, FLIP or IAPs (XIAP and survivin) by siRNAs sensitizes resistant melanoma cells to Apo2L/TRAIL-induced apoptosis. Cell Death Differ. 2004; 11(8):915-923.

44. LeBlanc HN and Ashkenazi A. Apo2L/TRAIL and its death and decoy receptors. Cell Death Differ. 2003; 10(1):66-75.

45. Zhao Y, Li Y, Wang L, Yang H, Wang Q, Qi H, Li S, Zhou P, Liang P and Li X. microRNA response elementsregulated TRAIL expression shows specific survivalsuppressing activity on bladder cancer. J Exp Clin Cancer Res. 2013; 32:10.

46. Garofalo M, Jeon YJ, Nuovo GJ, Middleton J, Secchiero P, Joshi P, Alder H, Nazaryan N, Di Leva G, Romano G, Crawford M, Nana-Sinkam P and Croce CM. MiR-34a/cDependent PDGFR-alpha/beta Downregulation Inhibits Tumorigenesis and Enhances TRAIL-Induced Apoptosis in Lung Cancer. PLoS One. 2013; 8(6):e67581.

47. Romano G, Acunzo M, Garofalo M, Di Leva G, Cascione
L, Zanca C, Bolon B, Condorelli G and Croce CM. MiR494 is regulated by ERK1/2 and modulates TRAILinduced apoptosis in non-small-cell lung cancer through BIM down-regulation. Proc Natl Acad Sci U S A. 2012; 109(41):16570-16575.

48. Wu H, Huang M, Cao P, Wang T, Shu Y and Liu P. MiR-135a targets JAK2 and inhibits gastric cancer cell proliferation. Cancer Biol Ther. 2012; 13(5):281-288.

49. Golubovskaya VM, Sumbler B, Ho B, Yemma M and Cance WG. MiR-138 and MiR-135 Directly Target Focal Adhesion Kinase, Inhibit Cell Invasion, and Increase Sensitivity to Chemotherapy in Cancer Cells. Anticancer Agents Med Chem. 2013; 14(1):18-28.

50. Chou TC. Drug combination studies and their synergy quantification using the Chou-Talalay method. Cancer research. 2010; 70(2):440-446. 